Lima, 3-4 de junio de 2009

\title{
Taller «Gobernanza Económica Indígena en
} América Latina»

Lima, 3-4 de junio de 2009

\section{Claude Le Gouill}

\section{OpenEdition}

Journals

Edición electrónica

URL: http://journals.openedition.org/bifea/2754

DOI: 10.4000/bifea.2754

ISSN: 2076-5827

\section{Editor}

Institut Français d'Études Andines

\section{Edición impresa}

Fecha de publicación: 1 agosto 2009

Paginación: 385-388

ISSN: 0303-7495

\section{Referencia electrónica}

Claude Le Gouill, «Taller «Gobernanza Económica Indígena en América Latina» », Bulletin de l'Institut

français d'études andines [En línea], 38 (2) | 2009, Publicado el 01 febrero 2010, consultado el 27 noviembre 2020. URL : http://journals.openedition.org/bifea/2754 ; DOI : https://doi.org/10.4000/ bifea. 2754

Les contenus du Bulletin de l'Institut français d'études andines sont mis à disposition selon les termes de la licence Creative Commons Attribution - Pas d'Utilisation Commerciale - Pas de Modification 4.0 International. 


\title{
Eventos
}

\section{TALLER «GOBERNANZA ECONÓMICA INDÍGENA EN AMÉRICA LATINA»}

\author{
Lima, 3-4 de junio de 2009
}

En 2008 se inició el proyecto «Pueblos Indígenas y Gobernanza Económica Pública y Privada en Latinoamérica», financiado por el Banco Interamericano de Desarrollo (BID), agrupando, bajo la responsabilidad de C. Gros y J. Foyer, investigadores que provenían, en su gran mayoría, del equipo del Ersipal-Credal del Instituto de Altos Estudios de América Latina (IHEAL, Sorbonne-Nouvelle París 3).

Entre enero y abril de este año, siete equipos de investigadores realizaron estudios de campo en diferentes países de América Latina para investigar la problemática propuesta por el BID. En base a estas investigaciones, cada equipo entregó un informe que debe ser publicado en el sitio web del Banco Interamericano de Desarrollo.

Aunque cada caso trataba una temática diferente, todas tenían que ver con el tema de la «gobernanza». Este concepto aparece, después de la Guerra Fría, a través de instituciones internacionales (Banco Mundial, ONU, OMC); pero también a nivel académico, en la ciencias políticas, con el objetivo de describir la nueva gestión del poder entre lo local y lo global. Incluye una idea despolitizada del poder gracias a la emergencia de nuevos actores, reagrupados bajo la denominación «sociedad civil». El término de gobernanza se refiere, entonces, al mismo tiempo a una idea despolitizada, policéntrica y multisectorial del poder.

A pesar de la connotación ideológica de esta nueva noción, impregnada en particular del discurso neoliberal triunfante en los años 1990, este término permite una nueva definición del poder al incorporar una dimensión más horizontal. Sin embargo, no hay que olvidarse de las grandes asimetrías que ahí se mantienen.

El término de gobernabilidad se refiere precisamente al ejercicio del poder en sí mismo al incorporar situaciones concretas de relaciones sociales (simétricas o no), las leyes que favorecen su aplicación y los valores propios a las poblaciones. Este término permite matizar el de «gobernanza» al incluir los contextos, las condiciones reales y los conflictos en la lucha por el poder. 
La última parte del proyecto reunió a los diferentes actores en la mesa redonda, «Gobernanza Económica Indígena en América Latina», organizada por el BID, el GITPA y el Instituto Francés de Estudios Andinos (IFEA) en Lima los días 3 y 4 de junio de 2009. Esta conferencia era un real ejercicio de gobernanza, reuniendo a la vez a una gran institución internacional (BID), a miembros de la sociedad civil ONG, en particular del GITPA (Grupo Internacional de Trabajo sobre Problemas Autóctonos), así como a un investigador y a dos representantes indígenas por cada estudio de caso.

Sin duda, se trata de una experiencia innovadora, basada en el diálogo y la concertación entre los actores oriundos de horizontes diversos, con la finalidad de buscar alternativas a las políticas de desarrollo e indigenistas impuestas desde arriba. Esas políticas, iniciadas en los albores del siglo XX con el indigenismo mexicano, muestran hoy sus límites. Los recientes acontecimientos en la Amazonía peruana demuestran la importancia de la concertación entre los actores, pero también la utilidad de algunos dispositivos implementados por los organismos internacionales, como la Declaración de la ONU sobre los Pueblos Indígenas.

La descentralización es el producto mismo de una mejor gobernabilidad nacional, impulsada a nivel internacional. El estudio del caso colombiano, presentado por Carlos Duarte, mostró que el sistema de «transferencias» impulsado por el Estado con la puesta en vigencia de la Constitución de 1991 no correspondió a los pedidos de las organizaciones indígenas. Las Entidades Territoriales Indígenas (ETIS) no han sido reconocidas hasta hoy, lo que provoca una dependencia de los resguardos frente a los municipios, departamentos y hasta el propio Estado, aunque los actores indígenas sean reconocidos como sujeto de derechos públicos.

Claude Le Gouill mostró que la descentralización boliviana, impulsada en la década de 1990, presenta otra forma de integración. En este caso, tanto las formas de organizaciones comunitarias como los territorios indígenas han sido obviados de la nueva estructura etática propuesta por la ley de Participación Popular de 1994. De ahí nace una subordinación de los territorios y organizaciones indígenas hacia los municipios dirigidos por la élite local, así como un dualismo entre autoridades tradicionales y nuevas autoridades del Estado. El reconocimiento de los territorios indígenas por la Ley INRA de 1996, por su lado, solo permitió en casos contados una verdadera «gestión territorial indígena» debido a la falta de financiamiento por parte del Estado, la ausencia de formación y los conflictos entre grupos de interés (indígenas, hacendados, concesiones mineras).

La descentralización impulsada en los diferentes países de América Latina provocó a menudo una terciarización de las políticas públicas. Es lo que demostraron Nadège Mazars y Bruno Barronnet para el caso de la salud y de la educación en Colombia. Este fenómeno marca la aparición de un tercer actor después del Estado y de las comunidades: la organización indígena como administradora de las políticas públicas. Sin embargo, este tipo de autonomía se enfrenta a las contradicciones existentes entre el discurso del Estado y la implementación real de las políticas, así como a la subordinación de las entidades indígenas frente a las entidades del Estado y a la falta de formación y de financiamiento. En casos 
así se enfrentan también dos visiones muy distintas de la educación y de la salud: una concepción «integral» indígena y una voluntad de privatización por parte del Estado.

Algunas formas de autonomía no serían sino «una autonomía por marginalización», como lo describe Christian Gros para el caso del territorio Conamarca Kuna Yala de los kunas de Panamá. Aunque esta autonomía sea un «factor estructurante excepcional para la gobernabilidad del territorio», conduce también a un abandono y una pauperización de la población indígena. Hoy es el propio Estado que amenaza esta autonomía por las grandes posibilidades turísticas del territorio Conamarca. Tal como lo demuestra este estudio, un fuerte grado de autonomía no es garante de una visión coherente del desarrollo entre los miembros de la comunidad; tampoco lo es de una ausencia de tensiones en el seno de la organización apenas surgen nuevos proyectos, en este caso el turismo.

Guillaume Fontaine hizo una presentación sobre la gestión de proyectos de hidrocarburos gracias al estudio de dos casos muy diferentes, Amazonía Gas en Ecuador y Camisea en Perú. Ello permitió vislumbrar otra dificultad de la «gobernanza indígena», relacionada a su articulación con las empresas privadas, a pesar de que el Estado siga siendo la contraparte privilegiada. El tema de los hidrocarburos es el que, sin duda, representa el mayor reto, tanto por la ganancia implicada y los grupos de interés involucrados como por las consecuencias a nivel mediombiental. El proyecto Amazonía Gas en Ecuador es un intento innovador de gestión de hidrocarburos por las propias organizaciones indígenas. La coyuntura de la época que reunía el gobierno liberal de Gutiérrez a las organizaciones indígenas, provocó una división del movimiento indígena e hizo fracasar el proyecto. Al contrario, en el Perú, a pesar de un contexto político particularmente desfavorable y de fuertes conflictos en los años 1990, las organizaciones indígenas, con el apoyo de los grupos medioambientalistas e indigenistas, lograron obtener una cierta cantidad de derechos, entre otros, territoriales y sacar beneficio de las ganancias petroleras. Los acontecimientos recientes en el Perú nos enseñan sin embargo el límite alcanzado por estos acuerdos, amenazados por nuevas politicas gobernamentales.

A través de las normas que implementa, el Estado estructura la gobernanza indígena, como fue señalado por Marike Michel para el caso de los bosques comunitarios en Guatemala. Sin embargo, este estudio revela también las incoherencias de algunas normas y proyectos de desarrollo cuando cohabitan cuatro formas de propiedades, lo que ocasiona confusión y una falta de gobernabilidad en la gestión forestal.

Las fuertes migaciones que conocen las poblaciones latinoamericanas son una de las consecuencias de las políticas económicas implementadas por el Estado que excluyen, a menudo, los «pequeños productores» del acceso al mercado. Ariana Estrada y Angélica López explicaron el papel de los microcréditos y de las remesas en Guatemala y México para mitigar las carencias de esas políticas. Las remesas permiten, ante todo, reembolsar el viaje o el consumo familiar en las comunidades; en cuanto a los microcréditos, financiados por las remesas, 
permiten crear verdaderos proyectos de desarrollo alternativos y complementarios a la migración y a la agricultura.

La integración al mercado económico y la crisis de la agricultura —principal actividad de las poblaciones indígenas - pueden tener repercusiones dramáticas en términos culturales e identitarios para los pueblos indígenas. Sin embargo, todos los representantes indígenas, presentes en Lima, manifestaron su voluntad de integrar el mercado y, sobre todo, de ser un actor central en este proceso. Asimismo los diferentes estudios de caso han demostrado que las organizaciones indígenas se ven reforzadas con esta integración. Esta articulación creciente al Estado y al mercado provocan, sin embargo, fuertes tensiones entre los pueblos indígenas así como una gran politización de sus autoridades. Eso conlleva siempre a más conflictos y competencias entre comunidades y grupos étnicos para lograr más desarrollo, una tensión más fuerte entre lo individual y lo colectivo y un alejamiento mayor entre la base y las nuevas autoridades indígenas. Para todos los casos presentados en el marco de esta mesa redonda, es indispensable una fuerte redistribución de los beneficios inter y/o intraétnicos a fin de limitar los conflictos. Adicionalmente, la construcción de un brazo técnico indígena y la diversificación de proyectos económicos para evitar la dependencia frente a una sola fuente de recursos, son otros factores de éxito de los proyectos económicos en territorio indígena. Ahora todos los actores indígenas hablan de «autonomía» para protegerse de cualquier subordinación y ser reconocidos en el plano político y económico. Esta autonomía no tiene nada de separatista sino que busca el constante apoyo del Estado.

Los representantes indígenas han mostrado las carencias del Estado en la implementación de las nuevas políticas indigenistas, en la falta de financiamiento y de formación de los líderes indígenas, así como la brecha que existe a menudo entre las leyes «indigenistas» y sus aplicaciones. Si no hay planificación del desarrollo, faltan además las estadísticas y las fuentes acerca de estas poblaciones y sus experiencias de gobernanza local.

Algunos logros muestran, sin embargo, que el «indígena» no es solo un objeto de estudio; es también un verdadero actor político y económico que se apoya en las ONG y la cooperación internacional para mitigar la falta de presencia del Estado. Busca su independencia frente a los políticos y los proyectos paternalistas gracias a la formación de un brazo técnico indígena que busca obtener el autodesarrollo de la organización y del territorio.

La mesa redonda en Lima permitió un verdadero encuentro multisectorial. Los actores indígenas han podido confrontar sus experiencias y expresar libremente sus opiniones y críticas para mejorar la gobernabilidad en los territorios indígenas. Para los investigadores fue una experiencia científica única pues les permitió analizar y comparar diferentes experiencias y discursos, gracias a un trabajo «participativo» a profundidad. Una futura publicación permitirá que un público más amplio llegue a conocer esta original experiencia de estudio de la «economía indígena». 